\title{
MODELLING THE EFFECTS OF A TIDAL LAGOON ON THE MORPHOLOGY OF SWANSEA BAY, WALES, UK
}

\author{
Jose M. Horrillo-Caraballo, Swansea University, J.M.Horrillo-Caraballo@swansea.ac.uk \\ lain Fairley, Swansea University, I.A.Fairley@swansea.ac.uk \\ Harshinie Karunarathna, Swansea University, H.U.Karunarathna@swansea.ac.uk \\ lan Masters, Swansea University, I.Masters@Swansea.ac.uk \\ Dominic E. Reeve, Swansea University, D.E.Reeve@swansea.ac.uk
}

\section{INTRODUCTION}

The Severn Estuary (west coast of UK) is a highly dynamic environment and thus understanding of sediment transport under both natural and man-made changes is vital to the sustainable use of the coastal area in this region. The area is likely to be the site of the world's first tidal energy lagoon. The construction and operation of the lagoon will result in some localised changes to hydrodynamic processes, leading to some potential changes in sediment transport and depositional processes at identified receptors within Swansea Bay (Fairley et al., 2014, Fairley et al., 2016, TLSB, 2016). There are some concerns about the possible impacts on the Site of Special Scientific Interest - SSSI (Blackpill and Crymlyn Burrows) and Kenfig Special Area of Conservation - SAC (not shown on figure), located Southeast of the tidal lagoon, see Figure 1.

A three dimensional hydrodynamics model (DELFT3D) of the Swansea bay area has been set up to investigate the sediment transport dynamics within Swansea Bay and longer term hydrodynamics of bedform features in the area. This project will underpin improved environmental understanding and coastal management in the Swansea Bay region (Figure 1) because the models produced will also provide input data for other projects reliant on tide, wave and sediment transport information in the area.

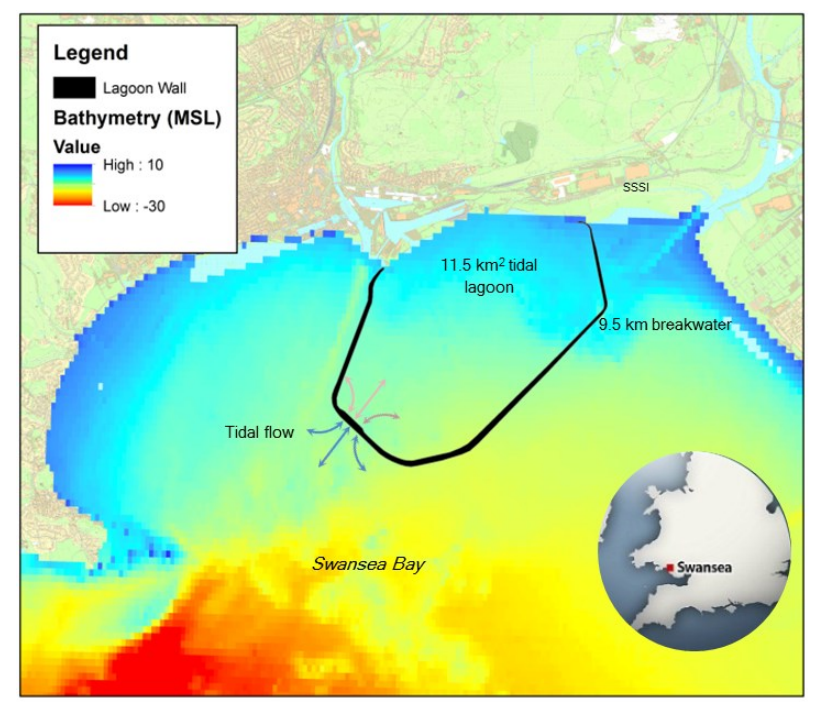

Figure 1 - Location of the Swansea Bay and Swansea tidal lagoon

\section{METHODOLOGY}

The primary objective of the project is to provide improved understanding of sediment movements and changes in seabed morphology in Swansea Bay and Bristol Channel areas. To do this, wave, tide and sediment transport models were developed. The wave model covered the North Atlantic to ensure accurate representation of swell waves (WaveWatch III). The tidal model (DELFT3D) covered the continental shelf region in order to accurately capture the progression and transformation of the tide wave in the coastal region. The tide model will be calibrated against available tide gauge and other published information. The wave model will be calibrated against various wave buoy records held at Swansea University. A range of grab sample datasets are available to define bed sediment for the sediment transport modelling.

The numerical modelling developed in this project will further help to understand in the large scale sediment transport patterns in the Bristol Channel and potential impact of lagoons, which is vital to the sustainable development of the sector. Furthermore, numerical modelling allows testing of different lagoon designs and operation strategies which will enable impact to be minimised. A key element of this project is to combine the predicted waves and tidal flows to drive a sediment transport model to assess sediment transport patterns under storm conditions. Model output will also be used to infer longer term sediment transport trends and to drive simpler models that can describe the medium to long term morphological evolution. The model output will be compared to records of historical evolution to test their performance. The tested models will then be used to evaluate a number of 'what if?' scenarios that are likely to alter the sediment transport patterns in the region to gauge the sense and magnitude of anthropogenic interventions.

\section{CONCLUDING REMARKS}

This study will improve understanding of the local morphodynamics which will reduce future consenting burden. Its model outputs (and derivatives) will be useful for assessing tidal lagoon impact as well as many aspects of local shoreline management.

\section{ACKNOWLEDGEMENTS}

The study was part-funded by the European Regional Development Fund through the Welsh Government via the SEACAMS2 project.

\section{REFERENCES}

Fairley, Ahmadian, Falconer, Willis, Masters (2014): The effects of a Severn Barrage on wave conditions in the Bristol Channel, Renewable Energy, vol. 68, pp. 428442.

Fairley, Masters, Karunarathna (2016): Numerical modelling of storm and surge events on offshore sandbanks, Marine Geology, vol. 371, pp. 106-119.

Tidal Lagoon Swansea Bay - TLSB (2016): Adaptive Environmental Management Plan. Report TLSB/DCO/ AEMP/18MAR16. Tidal Lagoon Swansea Bay Plc, 